\title{
Response to comments on: Nathan DM, Buse JB, Davidson MB et al. (2006) Management of hyperglycaemia in type 2 diabetes: a consensus algorithm for the initiation and adjustment of therapy. A consensus statement from the American Diabetes Association and the European Association for the Study of Diabetes. Diabetologia 49:1711-1721
}

\author{
D. M. Nathan • for the Consensus Group \\ Received: 23 October 2006 / Accepted: 25 October 2006 / Published online: 14 November 2006 \\ (C) Springer-Verlag 2006
}

To the Editor: We anticipated that our consensus algorithm $[1,2]$ would generate some controversy, but are pleased with the general level of appreciation expressed in the letters, albeit with some disagreements. P. E. Cryer specifically endorses the recommendation in our consensus algorithm to use insulin earlier in the treatment course of type 2 diabetes, but takes issue with the relatively low frequency of severe hypoglycaemia, defined as in the DCCT and compared with the rate in type 1 diabetes, that we cited [3]. As Dr. Cryer notes, our estimates were based on data from clinical trials aimed at normoglycaemia and achieving a mean $\mathrm{HbA}_{1 \mathrm{c}}$ of $\sim 7 \%$ [3]. Dr. Cryer cites review articles, including some referenced by us, and other empiric studies - not controlled clinical trials - that suggest a much higher risk for severe hypoglycaemia in insulin-treated type 2 diabetes than we described.

The reasons for choosing to use data from controlled clinical trials to establish the expected risk of severe hypoglycaemia with insulin therapy, rather than referring to the other clinical data referenced by Dr. Cryer, include the following: (1) more careful and uniform assessment of adverse events such as hypoglycaemia; (2) their use of

The members of the Consensus Group include D. M. Nathan (Chair), J. B. Buse, M. B. Davidson, R. J. Heine, R. R. Holman,

R. Sherwin and B. Zinman.

D. M. Nathan $(\bowtie)$

Massachusetts General Hospital Diabetes Center,

Harvard Medical School,

Boston, MA 02114, USA

e-mail: dnathan@partners.org consensus definitions established a priori; (3) their ability to compare frequency of hypoglycaemia among trials using 'intensive' therapy in type 1 and type 2 diabetes; and, perhaps most importantly, (4) their ability to examine the risk of hypoglycaemia in the setting of studies specifically aiming for and achieving glycaemic levels similar to those that we advocated. While we recognize that the selected cohorts and sometimes unrealistic setting of clinical trials may not accurately reflect what happens in clinical practice, we felt that the advantages noted above outweighed the potential problems associated with observational studies, and especially retrospective studies, that were cited in Dr. Cryer's letter.

Owing to space limitations, we did not include a comprehensive list of controlled clinical trials using insulin to achieve near-normoglycaemia with data supporting a relatively low rate of severe hypoglycaemia. However, we would draw attention to several large trials (a total of $>1,400$ participants), in addition to those cited in our original article, that utilized intermediate-acting insulin [4-6], long-acting insulin $[5,6]$, combinations of intermediate and rapidacting insulins [7], and insulin combined with oral agents $[4,6,7]$, and documented low rates of severe hypoglycaemia ( $0-5$ episodes per 100 patient-years) according to the DCCT definition. Moreover, large observational studies other than those cited by Dr. Cryer have noted rates considerably lower than those included in his table [8].

No one would argue that hypoglycaemia of any degree can be annoying and frightening for patients, and severe hypoglycaemia can potentially be life-threatening. However, we think that the best data, derived from the careful 
collection of events using uniform definitions in clinical trials, suggest a relatively low risk of severe hypoglycaemic events in insulin-treated type 2 diabetes. The ongoing Action to Control Cardiovascular Risk in Diabetes (ACCORD) study, which is aiming to achieve $\mathrm{HbA}_{1 \mathrm{c}}$ levels of $<6.0 \%$, should shed further light on the frequency of severe hypoglycaemia in insulin-treated type 2 diabetes [9]. We continue to endorse the algorithm proposed, including early use of insulin as indicated, mindful of the potential risks posed by each of the therapies.

M. Porta and M. Trento suggest that our algorithm dismissed the potential for lifestyle intervention to contribute to diabetes care, when we recommended that patients be treated initially with lifestyle plus metformin [10]. They further contend that we ignored a growing body of literature that supports lifestyle interventions, especially when delivered in a group setting, as a means of lowering $\mathrm{HbA}_{1 \mathrm{c}}$. However, the consensus document emphasises the importance of lifestyle intervention and recommends it as a first, and continuing, intervention in diabetes management. We also recommend treatment with metformin at the same time as initiation of lifestyle intervention as a realistic response to the common failure of lifestyle interventions in the clinical setting. This recommendation should not dissuade investigators or clinicians from developing and implementing innovative methods to enhance lifestyle interventions; it merely recognizes the absence of high-quality data to support the efficacy of solitary dietary treatment of type 2 diabetes, a conclusion of the recent Cochrane review cited by Drs. Porta and Trento [11]. In fact, in the study by Porta and Trento, the vast majority of the patients were treated with oral hypoglycaemic agents plus diet in order to maintain a stable $\mathrm{HbA}_{1 \mathrm{c}}$ level of $7.0-7.4 \%$ over 4 years [12]. While behavioural interventions, as implemented in the Diabetes Prevention Program [13] and ongoing Look AHEAD (Action for Health in Diabetes) study [14], may provide better glycaemic results than those accomplished in the past, widespread implementation of such interventions in usual clinical care has not yet occurred.

B. Schultes wonders why the consensus recommendations did not include bariatric surgery as another therapeutic option in the management of type 2 diabetes [15]. While we acknowledged the convincing observational data supporting the benefits of bariatric surgery, the relatively small proportion of the diabetic population that currently fulfils the criteria for bariatric surgery [16], and its limited worldwide availability, kept us from including it in the algorithm. There are patients for whom the benefits of bariatric surgery outweigh its risks, and it should be considered a therapeutic option for these individuals.

\section{References}

1. Nathan DM, Buse JB, Davidson MB et al (2006) Management of hyperglycaemia in type 2 diabetes: a consensus algorithm for the initiation and adjustment of therapy. A consensus statement from the American Diabetes Association and the European Association for the Study of Diabetes. Diabetologia 49:1711-1721

2. Nathan DM, Buse JB, Davidson MB et al (2006) Management of hyperglycemia in type 2 diabetes: a consensus algorithm for the initiation and adjustment of therapy. Diabetes Care 29: 1963-1972

3. Cryer PE. (2006) Comment on: Nathan DM, Buse JB, Davidson MB et al (2006) Management of hyperglycaemia in type 2 diabetes: a consensus algorithm for the initiation and adjustment of therapy. A consensus statement from the American Diabetes Association and the European Association for the Study of Diabetes. Diabetologia 49:1711-1721. Diabetologia DOI 10.1007/ s00125-006-0448-4

4. Yki-Jarvinen H, Ryysy L, Nikkila K et al (1999) Comparison of bedtime insulin regimens in patients with type 2 diabetes mellitus: a randomized, controlled trial. Ann Intern Med 130:389-396

5. Rosenstock J, Schwartz SL, Clark CM, Park GD, Donley DW, Edwards MB (2001) Basal insulin therapy in type 2 diabetes. Diabetes Care 24:631-636

6. Yki-Jarvinen H, Dressler A, Ziemen M and the HOE 901/3002 Study Group (2000) Less nocturnal hypoglycemia and better postdinner glucose control with bedtime insulin glargine compared with bedtime NPH insulin during insulin combination therapy in type 2 diabetes. Diabetes Care 23:1130-36

7. Janka HU, Plewe G, Riddle MC, Kliebe-Frisch C, Schweitzer MA, Yki-Jarvinen H (2005) Comparison of basal insulin added to oral agents versus twice daily premixed insulin as initial insulin therapy for type 2 diabetes. Diabetes Care 28:254-259

8. Miller CD, Phillips LS, Ziemer DC et al (2001) Hypoglycemia in patients with type 2 diabetes mellitus. Arch Intern Med 161: 1653-1659

9. Simons-Morton DG, Genuth S, Byington RP, Gerstein HC, Friedewald WT (2005) The burden of treatment failure in type 2 diabetes: response to Brown et al. Diabetes Care 28:761-762

10. Porta M, Trento M (2006) Comment on: Nathan DM, Buse JB, Davidson MB et al (2006) Management of hyperglycaemia in type 2 diabetes: a consensus algorithm for the initiation and adjustment of therapy. A consensus statement from the American Diabetes Association and the European Association for the Study of Diabetes. Diabetologia 49:1711-1721. Diabetologia DOI 10.1007/ s00125-006-0501-3

11. Moore H, Summerbell C, Hooper L et al (2004) Dietary advice for treatment of type 2 diabetes in adults. Cochrane Database Syst Rev CD004097

12. Trento M, Passera P, Bajardi M et al (2002) Lifestyle intervention by group care prevents deterioration of type II diabetes: a 4-year randomised controlled clinical trial. Diabetologia 45:1231-1239 
13. Knowler WC, Barrett-Connor E, Fowler S, for the DPP Research Group et al (2002) Reduction in incidence of Type 2 diabetes with life-style intervention or metformin. N Engl J Med 346:393-403

14. Look AHEAD Research Group (2003) Look AHEAD (Action for Health in Diabetes): design and methods for a clinical trial of weight loss for the prevention of cardiovascular disease in type 2 diabetes. Control Clin Trials 24:610-628

15. Schultes B (2006) Comment on: Nathan DM, Buse JB, Davidson MB et al. (2006) Management of hyperglycaemia in type 2 diabetes: a consensus algorithm for the initiation and adjustment of therapy. A consensus statement from the American Diabetes Association and the European Association for the Study of Diabetes. Diabetologia 49:1711-1721. Diabetologia DOI 10.1007/ s00125-006-0460-8

16. Snow P, Barry P, Fitterman N, Qaseem A, Weiss K (2005) Pharmacologic and surgical management of obesity in primary care: a clinical practice guideline from the American College of Physicians. Ann Intern Med 142:525-531 